\title{
Audit Tools and Techniques: Crucial Dimensions of Internal Audit Engagements in South Africa
}

\author{
Kgobalale Nebbel Motubatse $^{1 *}$, Marianne van Staden², Blanche Steyn ${ }^{3}$ and Lourens Erasmus ${ }^{4}$ \\ ${ }^{1,4}$ Tshwane University of Technology, ${ }^{2}$ University of South Africa, South Africa \\ ${ }^{3}$ University of Pretoria, South Africa \\ *E-mail: MotubatseKN@tut.ac.za
}

KEYWORDS Audit Engagements. Audit Tools and Techniques. Common Body of Knowledge. Internal Audit. Governance. Value Adding

\begin{abstract}
The paper presents secondary empirical data from the Common Body of Knowledge study, on the use of audit tools and techniques by internal auditors in South Africa and compared its findings on South African internal audit functions with those of developed regions. It investigates the current use of the audit tools and techniques by the internal auditors in South Africa. This paper also reviewed relevant literature to support arguments for the use of audit tools and techniques by the internal auditors. The study found that internal audit functions in South Africa use audit tools and techniques similar to that of developed regions. The paper also found that internal auditors mostly use audit tools and techniques, such as risk based planning electronic, communication, analytical reviews and working papers. The paper concludes that, while other audit tools and techniques are important to have, the most preferred enhances the quality of the audit process.
\end{abstract}

\section{INTRODUCTION}

The use of audit Tools and Techniques (TTs) are essential to any Internal Audit Function (IAF), as it could help internal auditors achieve their engagement objectives. The audit TTs discussed in this paper include, risk-based audit planning, Control Self-assessment (CSA), electronic working papers, statistical sampling, analytical reviews, quality assessment review tools and benchmarking, Computer Assisted Audit Techniques (CAATs), electronic communication and other computer audit tools. The importance of these audit TTs has been discussed exclusively, from various sources of literature (AbouEl-Sood et al. 2015; Kutum et al. 2015; Christensen et al. 2015; Jacobus 2015). Thus, the audit TTs are evolving aids, which support internal auditors in performing effective audit engagements (Dittenhofer 1994; Liebowitz et al. 2000; Burnaby and Hass 2009; Bailey 2010).

Based on the International Standards for the Professional Practice of Internal Auditing (Standards) (Institute of Internal Auditors (IIA) 2010), the audit TTs are crucial dimensions of any internal audit function. In South Africa, internal auditors are encouraged to comply with the Standards by governance regulations, such as the Public Finance Management Act (PFMA), Municipal Finance Management Act (MFMA), Treasury Regulations (Republic of South Africa (RSA) 2009) and the King III report (Institute of
Directors (IoD) 2009). Standard 1200 requires IAFs to "be performed with proficiency and due professional care”, and this is accomplished by possessing or obtaining "the knowledge, skills, and other competencies needed to perform its responsibilities”, as required by Standard 1210 (IIA 2010). Furthermore, Standard 1220 requires internal auditors to "apply the care and skill expected of a reasonably, prudent and competent internal auditor" in the same or similar circumstances of the engagement being performed (IIA 2010).

TTs are the toolbox of internal auditors that enable them to perform engagements with proficiency and due care, and they include, analytical review, balanced scorecard or similar framework, benchmarking, computer assisted audit techniques, continuous/real-time auditing, data mining, electronic work papers, flowchart software, other medium of electronic communication (for example, Internet, email), process mapping application, process modeling software, riskbased audit planning, the IIA's quality assessment review tools, and the total quality management techniques (Bailey 2010).

As such, competence in audit TTs is necessary and should be used appropriately, throughout the internal audit engagements. The steps in the audit engagement include, the determination of the audit objectives, scope, risk identification, planning, audit evidence, and commu- 
nicating results up to the follow-up processes (Burnaby and Hass 2009; IIA 2010).

According to Burnaby and Hass (2009), the use of TTs is an important role during audit engagements, assisting with the gathering of reliable audit results. Although, some research has been conducted on the audit TTs mentioned in this paper, no prior research could be found, in which the audit TTs are exclusively addressed (Flesher and De Magalhaes 1995; Thompson 2001; Hubbard 2002; Marais 2004; Martin 2004; Coetzee and Fourie 2009; Castanheira et al. 2010). Thus, there is no paper which had inclusively dealt with the literature on audit TTs.

The remainder of this paper is developed to illustrate the objectives of the study, the literature review on the various TTs, as well as methods, results and discussion, conclusion, and recommendations.

\section{Objectives of the Study}

The purpose of this paper is to investigate the current use of the audit TTs in a South African context. This is accomplished through the reviewing of the theory to provide a concise background on the nature, use, and benefits of each audit TT, analyzing the year 2010 Common Body Of Knowledge (CBOK) results, on the use of audit TTs by internal auditors in South Africa, and discussing findings on South African IAFs as compared with that of other African countries, the United Kingdom and Ireland, Australia, and North America.

This paper provides a literature review to ground the empirical results and to build a sound overview of literature on the audit TTs, currently used by internal auditors.

\section{Literature Review}

In providing more background knowledge on the nature of the most important and most used audit TTs, as identified by the 2010 CBOK study, the following literature review provides a detailed discussion of the more important audit TTs, which includes risk-based audit planning, Control Self-assessment (CSA), electronic working papers, statistical sampling, analytical reviews, quality assessment review tools and benchmarking, Computer Assisted Audit Techniques (CAATs), electronic communication and other computer audit tools.

\section{Risk-based Audit Planning}

According to Griffiths (2006), the concept of risk-based audit planning is used by internal auditors to ensure that their audit efforts focus on providing assurance that the risk management of the organization are in line with its risk appetite. Throughout this paper, the term 'risk management' is used to describe the process of identifying, analyzing and mitigating the possible effects on achieving the organization's objectives. The internal auditor provides an assurance on risk management, when he or she assesses the adequacy and the effectiveness of controls and governance processes (IIA 2010). Following the experiences of recent factors associated with the adoption of the risk-based audit planning, Castanheira et al. (2010) showed that using risk-based audit planning could help internal auditors better understand the organization's strategic direction. In addition, Castanheira et al. (2010) noted that "[r]isk-based internal auditing helps companies practice effective risk management, because it incorporates the principles of risk management throughout the audit process, both in the annual planning process, and in planning each audit engagement”. Siers and Blyskal (1987) stated that once the risk is identified and measured, it can be managed by allocating resources to test the control climate of the risk strata.

Furthermore, the study by Castanheira et al. (2010) indicates that the adoption of risk-based audit planning is significantly and positively related to the organization's size, with internal audit, following a more proactive and more consulting orientated role in the establishment of risk management in smaller organizations.

Standard 2120 mandates that "the IAF must evaluate the effectiveness and contribute to the improvement of risk management processes" (IIA 2010). This therefore, is the focus of risk-based audit planning, as it requires an auditor to understand every aspect of the organization being audited, including its IT risks and controls, to enable the auditors achieve the objectives of the audit plan (Schroeder and Singleton 2010).

The recent exploration by Pokrovac et al. (2010) on the effectiveness of a risk-based approach by internal auditors indicate its importance as a contributor to the creation of added value. In order to promote the principle of adding value, the risk-based audit planning is aimed 
at helping internal auditors undertake continuous assessment, in order to render suggestions to management for the improvement of the risk management process. Risk-based audit planning requires that the internal auditor assess the effectiveness of the internal controls being implemented by management to mitigate the identified risk. The internal auditor is therefore, in a position to add value to the organization by recommending necessary improvements to internal controls. Internal controls form an indispensable part of risk management, and improved internal controls create the possibility of improving the overall risk management process in the organization (Pokrovac et al. 2010). Danescu et al. (2010) also addressed value that can be added and stated that the risk-based audit planning is a tool, which allows the auditor to offer comments and advice to the organization's management, regarding business risks. Since internal auditors moved towards the risk-based audit planning, Griffiths (2006) reported that understanding the risk and the monitoring of controls, require a complete risk register.

Coetzee and Fourie (2009) reported that internal auditors are beginning to optimize the use of risk-based audits in their plans and internal audit engagements. The theoretical aspects of Standard 2110 (IIA 2010), as well as the relevance of risk-based audit planning tools, are underpinned in the King III report, under principle 7.2, namely "that the IAF should pursue a risk-based approach to planning, as opposed to a compliance approach, that is limited to the evaluation of adherence to procedures. A risk-based internal audit approach has the benefit of assessing whether the process, which is intended to serve as a control, is an appropriate risk measure” (IoD 2009). As a result, it could be further argued that in South Africa, a risk-based audit planning is required by the governance frameworks. Companies listed are also required to comply with this.

\section{Control Self-assessment (CSA)}

One of the fundamental audit TTs affecting the internal audit related to understanding the risks, controls and governance processes, is a Control Self-assessment (CSA) (Jacobus 2015; Melville 1999; Allegrini and D’Onza 2003; Sheffield and White 2004). CSA is often defined as a process whereby an organization's personnel, evaluate their own risks and controls with the help of facilitators from the IAF (Engle and Joseph 2001; Hubbard 2002; Joseph and Engle 2005). According to the latter, internal auditors use CSA to assess financial statement risks, the controls directed at those risks, and compliance with laws and organizational procedures.

The transformational role of the internal audit which facilitates the structural overall effort and audit universe, makes the CSA an effective TT in the contemporary performance and engagement audit (Barker and Graham 1996). The recognition of the CSA by internal auditors indicates that it is a technique used to link the risks, business objectives, and controls within organizations (McCuaig 1998). Furthermore, when compared with traditional internal audit procedures, the application of CSA techniques sharpens the internal auditor's focus and facilitates more meaningful CSA sessions with wider audit coverage in an organization, at a lower cost (Adamec et al. 2002). Therefore, the implementation of the CSA remains a cost effective technique, for internal auditors to accomplish their tasks.

Being mindful of this, Fernandez-Laviada (2007) emphasized that the IAF should continually be alert to the implementation of systems for managing operational risks in organizations by modifying their forms of behavior and adopting their procedures, from the point of its supervision, to the creation of a strong culture, which reinforces the frameworks and promotes a sound operational risk management. Carter (2007) pointed out that the CSA can offer a possible solution to aspects of Section 404 of the SarbanesOxley Act of year 2002 on compliance and challenges, which require the auditor to report on the effectiveness of internal control over financial reporting. It is pertinent to know that the CSA techniques are more flexible to customization in all business functions and compliance frameworks (Graves et al. 2003).

\section{Electronic Working Papers}

Electronic working papers are the recordings of the audit working papers in an electronic format with CaseWare, which is an example of a program that can be used to generate electronic working papers. Although, electronic working papers are widely used as audit TTs by the internal auditors, Standard 2330 (IIA 2010) indicates that the work of the IAF should be record- 
ed. This can be done manually, supported by "paper" audit working papers in physical files, or electronically, with electronic working papers saved on a computer or a server. The core recommendations of Standard 2330 (IIA 2010) is that the working papers should be prepared by the internal auditors and reviewed by the management of the IAFs, in order to provide the principal support for engagement communications, aid in the planning, performance and review of engagement, as a means of documenting whether the engagement objectives were achieved, facilitate third party reviews, provide a basis for evaluating the IAF quality program, provide support in circumstances, such as insurance claims, fraud cases and lawsuits, aid in the professional development of the internal audit staff, and demonstrate the IAF's compliance with the Standards.

Flesher and De Magalhaes (1995) described the advantages of electronic working papers, such as auditors being able to review and share audit files from various locations, since data which has been electronically stored, can be retrieved from the database. It can also help with the retention of working papers, as the electronic working papers can be centrally stored with proper backup routines. With the exception of the study on the 2010 CBOK survey, relatively little research has been made on the contemporary use of the electronic working paper in South Africa. However, as technology is replacing the traditional ways of conducting business, it is becoming clear that the technological consequences of using electronic, as opposed to manual working papers, is an area that can be researched in depth in the future.

Flesher and De Magalhaes (1995) also investigated the possibility that the automation of the audit working papers may be the first step in transforming the IAF's procedures and practices. Their study further found that the paperless systems can improve the quality and efficiency of IAFs and can help in fostering new and creative approaches to auditing. The value of electronic working papers, especifically CaseWare, can be summarized as:

- Efficiency: CaseWare has a proven track record of significantly increasing engagement efficiency and the preparation of financial statements up to a hundred percent.

- Compliance: The expert content partners, both locally and globally, consistently pro- vide the most up-to-date disclosure for International Financial Reporting Standards (IFRS) for Small and Medium Enterprise (SME) and Generally Recognized Accounting Practice (GRAP) as well as the International Standards on Auditing.

- Control: CaseWare enables users to electronically manage the entire audit process from planning to the review stage. CaseWare's built-in validation immediately brings any discrepancies to attention (CQS 2013).

As technology continues to improve and become more persistent, the use of electronic working papers can be a tool used by auditors to improve the efficiency and effectiveness of internal audit engagements.

\section{Statistical Sampling}

Statistical sampling is the use of statistical methods to identify the size of a sample, select the sampling units, and interpret the data, to enable the results to be projected to the underlying population. Statistical sampling is defined as "the process of selecting elements of a population for either descriptive or inferential purposes” (Barron's Business Dictionary s.v statistical sampling). Statistical sampling has been a central audit TT of internal auditors in audit engagement, and it has been discussed by various writers (Hall et al. 2002; Lamb et al. 2009; Schreiner 2009). Nevertheless, the information shared on how the "sample made simple audit" by Martin (2004), found that auditors are often called upon to test internal controls through attribute sampling. This process involves the selection of a sample of transactions from a population of data, and testing for the presence or absence of certain attributes and qualities (Martin 2004: 21). Sampling can also be focused on values or amounts, where less than hundred percent (100\%) of the population is selected for testing, and the results are used to draw a conclusion about the value of the entire population. Both are used by internal auditors to save time, effort and expenses that may be involved in testing the whole population (Colbert 2001). Clearly, statistical sampling can assist internal auditors to use their audit resources as effectively as possible, by testing a sample and extending the results of that sample to the whole population. 


\section{Analytical Review}

Analytical review is defined as an "[a]uditing process that tests the relationships between accounts and identifies material changes. It involves analyzing significant ratios and trends for unusual changes and questionable items" (Barron's Business Dictionary s.v. analytical review). Similarly, the use of analytical reviews has been highlighted as the audit TT to spot material errors during the audit engagement (Christensen et al. 2015; Choo et al. 1997). Having used the analytical review as a typical audit engagement, Sawyer et al. (2003) observed that analytical reviews have long been used to determine the reasonableness of certain data relating to financial matters, by comparing the financial information of the current period with that of previous periods. Therefore, analytical reviews should be a powerful audit TTs, which have the potential of boosting the efficiency of internal audit engagement, and limiting the time and effort needed to understand the business functions.

\section{Quality Assessment Review Tools and Benchmarking}

The quality assessment review tool has also become a core audit TT, in improving the IAF's value within the organization. A considerable work of literature, prepared by Lin et al. (2011), indicated that a quality assessment review tool helps IAFs in the field, to be more effective and focused on their direct supervision activities, independent working paper reviews, request for audit client feedback, undergoing peer review by fellow staff members (McCabe et al. 2007), and the use of working paper checklists.

With the specific requirements of Standard 1310 (IIA 2010), a quality assurance and improvement program must include both internal and external assessments. Similarly, the interpretation of this Standard enable internal auditors possess the knowledge, skills, and other competencies necessary to manage the IAF, and to understand all elements of the International Professional Practice Framework (IPPF). Viewed from the perspective of the Standards, Brune (2000) reported that the quality assurance review tools help IAFs in identifying problematic areas and also help improve the quality, efficiency and effectiveness of the organization's services. It is interesting to further note that similar sentiments were shared by Marais (2004) on the analysis of quality assurance auditing, which recognizes that all auditors and managers are required to audit and manage quality assessment reviews, effectively.

Although the quality assessment review tool has now been emphasized in the Standards, Plumly and Dudley (2002) acknowledged that the quality improvement program has always been an important aspect of the internal auditing's overall processes and improvement initiatives. Thus, from the audit planning, fieldwork, drafting of audit reports, final audit reporting, primary audit working papers, audit follow-ups, and customer service, to a full-time audit, quality improvement development enhances the IAF approaches. From a compliance perspective, McCabe et al. (2007) suggested that the use of the IIA quality assessment review tools will provide internal auditors with excellent opportunities to improve their functions and customer satisfaction.

Generally, internal auditors could use the benchmarking tool to evaluate different aspects of their organization's processes. According to Moeller (2009), benchmarking is key to the internal auditors' recommendations when reviewing operations. Seeing as benchmarking increases the efficiency of operations, Cooper et al. (1996) argued that it is a powerful audit tool that compels the critical review of existing audit processes, which leads to a better understanding of actual, rather than perceived work performance by auditors.

\section{Computer Assisted Audit Techniques (CAATs), Other Computer Audit Tools and Electronic Communication}

There are several publications on the reality of CAATs as an effective TT in the IAFs (Zacchea 1995; Rezaee and Reinstein 1998; Braun and Davis 2003; Abu-Musa 2008). CAATs include any kind of technology that can be used to assist the completion of an audit engagement (Braun and Davis 2003). Thus, the use of CAATs among internal auditors is common and unavoidable. Information Technology (IT) has been identified as one of the most difficult internal audit speciality functions among contemporary internal auditors (Sumners and Soileau 2008). Nonetheless, in spite of the challenges, Sumners and Soileau (2008) maintained that IT and the IAF 
could provide significant benefits in transferring the knowledge necessary in building the potential independence and objectivity to improve work performance and relationships in the audit engagement.

Glover and Romney (1998) revealed that IT has become an integral part of the IAF and is increasingly important as it benefits the evaluation of the reliability of financial data, among internal auditors in countries, such as Switzerland, Canada, the Philippines, Thailand, Malaysia, Spain, South Africa, and the United States. Furthermore, the IAFs using IT products are realizing the benefits of data extraction, analysis and the prevention and detection of fraud, through audit of electronic commerce. Therefore, CAATs are a cutting edge, internal audit tool used to run specific audits in the organizations (Glover and Romney 1998).

Teeter et al. (2010) commented that the extent to which auditors can employ CAATs varies, depending on the auditor's expertise. Therefore, when evaluating which tools to use and develop for a remote audit, the auditors can use the existing CAATs, as a fundamental tool in real-time data assessment and automatic evidence collection. Unlike other internal audit TTs, the CAATs enable the auditor to support compliance issues in a systematic, timely, and continuous manner; it also offers critical technological solutions in order to ensure the organization's ongoing survival and competitiveness (Hudson 1998).

In a comprehensive review of what "CAATs can do" presented by Thompson (2001), it indicated that using CAATs, may be the best way to identify fraud. This entails identifying ghosts on the payroll, potential fictitious employees and fraudulent incidents, as well uncovering similar cases involving other perpetrators. It encourages better investigations, fixes control weaknesses, and also reviews all controls, when making changes to procedures, which helps with strategies to report the incidence of fraud to the law enforcement agencies and assists law enforcement agencies in performing better investigations (Thompson 2001). Interestingly, Vuchnich (2008) concluded that using CAATs in the audit engagements can enhance the response to the risks of substantive tests.

CAATs use IT to assist auditors with the execution of the audit engagement (Flowerday et al. 2006). Burnaby et al. (2006) stated that
CAATs are an emerging trend and their use is becoming a common practice in many regions of the world. However, the use of specific CAATs, such as continuous auditing, has declined among internal auditors in South Africa. It is important to note that the results of the 2006 CBOK survey indicated that the continuous audit tool ranked seventy percent, whereas in the year 2010 CBOK survey, it ranked below forty percent (IIARF 2010). The reason behind this decline is not evident from the data and will need to be identified in future research. Such research can also include the identification of which of the various programs used for CAATs (that is, ACL) is increasing or decreasing in popularity, as well as how they are mostly used. This can be an important future research contribution, as CAATs can be used for different audit purposes including, but not limited to, the extraction of source documents, transactions or balances for samples, the extraction of unusual transactions that are outside the specified parameters (continuous audit), or the identification of possible fraudulent transactions (data mining) for further substantive procedures.

Kuhn and Sutton (2010) stated that continuous auditing is considered an effective audit tool among external auditors. However, Garrity et al. (2006) considered the data mining techniques a suitable audit tool in evaluating continuous auditing generated data. Reasonably, data mining is viewed as a tool to discover unknown information from a large set of data, which is useful evidence by auditors (Garrity et al. 2006; Valls de Almeida and Pedrosa 2011).

The trend in the use of computer programs, such as email and Internet, is on the increase in South Africa. Thus, the use of other electronic communications, such as emails and Internet ranked eighty percent in the year 2010 CBOK survey, closely associated with the risk-based audit planning. It was similarly ranked at seventy percent in the year 2006 CBOK survey, which was also equivalent to the ranked importance of risk-based audit planning (IIARF 2010). By having access to electronic communications, internal auditors can fast track communication between audit teams and their audit customers. With this observation, Pathak et al. (2010) summarized that the auditing context has been transformed from simple electronic financial records to electronic media, such as email and chat messaging. Through the use of electronic communi- 
cations, auditors benefit from the value of accessing the requested audit information from their customers in time.

\section{METHODOLOGY}

The IIA sent a web-based survey instrument in year 2006 and in year 2010 to their members and non-members across the globe, in order to gather data for the CBOK study. This paper used the IIARF's CBOK research database (with the IIASA's permission) as a secondary source. The method used to analyze the data for this paper is a comparative analysis that seeks to compare the year 2006 and year 2010 survey results on the use of audit TTs among South African respondents, respondents from the rest of Africa, and other specific regions. Comparative research is the act of comparing two or more things with a view of discovering something about one or all of the things being compared (WebFinance, Inc. 2010).

The year 2010 CBOK survey contained 13,577 responses by IIA members and non-members in more than 107 countries. The main analysis in this study was based on 294 respondents from South Africa, who participated in the study along with the following respondents from specific regions:

- The rest of Africa (excluding South Africa) $-337$

- Ireland and the United Kingdom (UK) - 657

- Australia - 206

- North America - 3582

\section{RESULTS AND DISCUSSION}

The discussion and analysis in this paper address the published 2010 CBOK results on the use of TTs by internal auditors in South Africa. A further analysis and discussion compares TTs that South African IAFs consider to be important for the future, with the opinions of the rest of Africa (excluding South Africa), Ireland and the United Kingdom, Australia, and North America. From the year 2006 and the year 2010 CBOK survey, the South African respondents have shown their reliance on the use of audit TTs, such as the risk-based audit planning, electronic working papers, statistical sampling, analytical reviews, computer assisted audit techniques and other electronic communications, control self-assessment, quality assessment re- view tools and benchmarking. The results observed from the published 2010 CBOK results indicate that the risk-based audit planning has been widely accepted by internal auditors as a means to identify measures and prioritize the IAF's allocation of resources. Perhaps, the high ranking of risk-based audit planning could possibly indicate that internal auditors are serious about the assurance they give, as well as in compliance to the principles of risk-based auditing. The importance, as rated by the respondents of the CBOK results, is of particular interest, as South Africa is in line with other developed regions, such as Australia and North America, especially in the use of the risk-based audit planning tools. In fact, South Africa made use of the quality assurance review tool more than the other regions. Therefore, the risk based audit planning and other electronic communication were the most preferred audit TTs. Otherwise, all the other audit TTs were the most preferred in the year 2006 as opposed to year 2010 CBOK results (IIASA 2012). It was also illustrated in these studies that the preferred audit TTs used by internal auditors per region, differed.

Similarly, the high usage of other means of electronic communication is an indication that internal auditors are using electronic communication channels to facilitate the process of sharing and exchanging ideas, with their customers and peers. This could also mean that most South African organizations have evolved practices that use electronic communication, and internal auditors are merely using the existing infrastructure to communicate. This response could further indicate that internal auditors view emails as an effective tool in enhancing their audit engagements.

To obtain a better understanding of the use of TTs by South African IAFs, Table 1 shows the use of TTs in the public sector and listed companies.

IAFs in South Africa, from both public and private sectors, use audit TTs, such as the riskbased audit planning, electronic working papers, and analytical review, more than other TTs. This high ranking is possibly due to the fact that riskbased audit planning helps internal auditors address and prioritize high risk areas in their audit plans. It also helps internal auditors follow an appropriate audit methodology. The high use of electronic work papers (89.53\%) in the public sector and (86.42\%) the private sector, could be 
Table 1: Use of TTs by the South African public sector and listed companies

\begin{tabular}{lcr}
\hline & $\begin{array}{l}\text { Public } \\
\text { sector } \\
\text { (in per- } \\
\text { cent) }\end{array}$ & $\begin{array}{c}\text { Listed } \\
\text { companies } \\
\text { (in per- } \\
\text { cent) }\end{array}$ \\
\hline Risk-based audit planning & 90.69 & 91.35 \\
Electronic work papers & 89.53 & 86.42 \\
Analytical review & 77.77 & 74.41 \\
Computer assisted audit & 59.30 & 71.60 \\
$\quad$ technique & 37.20 & 49.38 \\
Control self-assessment & 67.44 & 37.04 \\
Quality assessment review tools & 33.72 & 39.27 \\
Continuous/real-time auditing & 33.72 & 55.55 \\
Data mining & 59.30 & 46.91 \\
Benchmarking & 63.95 & 58.02 \\
Statistical sampling & 38.37 & 48.15 \\
Flowchart software & 16.28 & 14.81 \\
Process mapping application & 37.20 & 32.09 \\
Balanced scorecard or similar & & \\
$\quad$ framework & & \\
\hline
\end{tabular}

Source: Generated by the authors

due to an improved control and back-up over electronic working papers or other benefits, such as reducing the amount of time needed for review as well as the value of being able to review electronic working papers remotely. Analytical reviews are rated at third position by both sectors $(77.77 \%)$ in the public sector and (74.41\%) the private sector. This implies that internal auditors are using the analytical reviews to better understand the organization's risk management, controls and governance processes. The lower rated use of CAATs by the public sector (59.30\% versus $71.60 \%$ in the private sector) shows that despite the increased use of electronic working papers, IT skills might still be a challenge among internal auditors in the public sector. The use of quality assessment review tools show that the public sector is consistently following the review processes using the tools of the IIA. This could be encouraged by the fact that the public sector internal auditors are striving to comply with the Standards, but it can also indicate the value of regulation as the PFMA and MFMA requires compliance with the Standards. Hence, the rest of the TTs are not highly rated by either sector, and may encourage opportunities for further research to determine their extent of usage by the internal auditors, in their audit engagement.

South African respondents considered electronic working papers, analytical reviews, CAATs, CSA, quality assessment review tools, continuous auditing, data mining, benchmark- ing, statistical sampling, flowchart software, process mapping application, total quality management, balanced scorecard, and process modeling software to be important audit tools in enhancing the audit processes. However, the use of risk-based audit planning, electronic working papers, analytical review and other electronic working papers are ranked very important, as indicated by more than eighty percent (80\%) of South African respondents. These may be explained by the analysis and discussions of the year 2010 CBOK results on the use of audit TTs by South African IAFs, and the comparison of this usage with the other regions gives an insight into the audit TTs, preferred by internal auditors in South Africa. The review of theoretical literature also provides and supports the findings on the significance of the use of the audit TTs. Therefore, by looking at the anticipated use of audit TTs over the five years by specific regions, as indicated in the CBOK study, one sees that risk-based audit planning, electronic working papers, analytical reviews, CAATs, CSA, quality assessment review tools and other electronic communications, were ranked highly at between (74.02\% to $95.06 \%)$ respectively, by the South African respondents (IIASA 2012).

\section{CONCLUSION}

This paper highlighted that the TTs are currently preferred by the South African internal auditors and compared the important TTs which are to be used in five years between South Africa and other specific regions. The results of the secondary data analysis of the CBOK study indicate that the internal auditors were using the risk based audit planning and other electronic communications, such as emails and other internal communication programs to enhance the efficiency of their audit process and the quality of audit reports. This paper also compared the responses of South African internal auditors and the practitioners' views on the importance of TTs in the future, with the responses from other regions. It was discovered that IAFs in South Africa make use of TTs, similar to those used in other, more developed regions, such as Australia and North America.

Currently, risk-based audit planning, electronic communications, analytical reviews, electronic working papers and CAATs are the most fre- 
quently used audit TTs in South Africa, which is in line with international trends and show that South Africa embraced and used new TTs.

As for the remaining audit TTs, such as the total quality management, the balance scorecard, process mapping, process modeling software, data mining and benchmarking, were used less by South African respondents. Further research should be undertaken to understand the reasons that lead to a reduced use of some TTs. Despite the limitations identified, this paper could contribute to the skills and knowledge of the internal auditors in the performance of the audit engagement. The improved use of TTs can result in a better risk-focused, more efficient and effective audit. This paper concludes that TTs strengthen the IAFs work, which result in an improved audit report to better add value to the auditee. Thus, the TTs assist the IAFs in delivering the audit plan on time, by accomplishing or meeting up with their targets. Furthermore, it could benefit the IIASA to prioritize the internal auditors' training needs on audit TTs, especially if under-used TTs are due to a lack of training or skills shortage.

\section{RECOMMENDATIONS}

Based on the number of audit TTs available for use by the internal auditors, the paper suggests that the chief audit executives should consider all TTs in the efficient and effective planning as well as the management of audit engagements. The paper also recommends that the IIA in South Africa should use the gaps in the use of TTs to plan and update its training materials for the continuing educational program of internal auditors' skills. Indeed the chief audit executives should identify the importance of audit TTs in the planning stage of the audit process. Thus, the paper recommends that the internal auditors should enhance their competence in the use and application of these audit TTs.

\section{REFERENCES}

Abou El Sood H, Kotb A, Allam A 2015. Exploring auditors' perceptions of the usage and importance of audit information technology. International Journal of Auditing, 19(3): 252-256.

Abu-Musa AA 2008. Information technology and its implications for internal auditing: An empirical study of Saudi organisations. Managerial Auditing Journal, 23(5): 438-466.
Adamec BA, Rexroad WM, Leinicke LM, Ostrosky JA 2002. Internal reflection. Internal Auditor, 59(6): 56-63.

Allegrini M, D’Onza G 2003. Internal auditing and risk assessment in large Italian companies: An empirical survey. International Journal of Auditing, 7(3): 191208.

Bailey JA 2010. Core Competencies for Today's Internal Auditor: Report II. The IIA Research Foundation, Altamonte Springs, FL: The IIARF.

Barker LL, Graham RD 1996. Control self-assessment. Internal Auditor, 53(2): 52-57.

Barron's Business Dictionary. Dictionary. [Online]. Answers.com. From <http: //www.answers. com/topic.>. (Retrieved on 27 February 2013).

Braun RL, Davis HE 2003. Computer assisted audit tools and techniques: Analysis and perspectives. Managerial Auditing Journal, 18(9): 725-731.

Brune C 2000. Internal audit issues analysed. Internal Auditor, 57(5): 14-15.

Burnaby P, Hass S 2009. A summary of Global Common Body of Knowledge 2006 (CBOK) study in internal auditing. Managerial Auditing Journal, 24(9): 813-834.

Burnaby P, Hass S, Abdolmohammadi AJ 2006. A survey of internal auditors to establish the scope of the Common Body of Knowledge study in 2006. Managerial Auditing Journal, 21(8): 854-868.

Carter C 2007. Compliance through self-assessment. Internal Auditor, 64(2): 69-72.

Castanheira N, Rodrigues LL, Craig R 2010. Factors associated with the adoption of risk based internal auditing. Managerial Auditing Journal, 25(1): 7998.

Choo TM, Chua MK, Ong CB, Tan TH 1997. Analytical procedures for new and matured industries. Managerial Auditing Journal, 12(3): 123-134.

Christensen BE, Elder RJ, Glover SM 2015. Behind the numbers: Insights into large audit firm sampling policies. Accounting Horizons, 29(1): 61-81.

Coetzee P, Fourie H 2009. Perceptions on the role of internal audit function in respect of risk. African Journal of Business Management, 3(13): 959-968.

Colbert JL 2001. Audit sampling. Internal Auditor, 58(1): 27-29.

Cooper BJ, Leung P, Mathews CMH 1996. Benchmarking a comparison of internal audit in Australia, Malaysia and Hong Kong. Managerial Auditing Journal, 11(1): 23-29.

CQS 2013. CaseWare Audit. [Online]. From <http: // www.cqs. co.za/caseware/caseware- audit/> (Retrieved on 27 February 2013).

Danescu T, Oltean (Muntean) A, Sandra R 2010. Riskbased internal audit: Perspectives offered to corporations and banks. Annales Universitatis Apulensis Series Oeconomica, 12(1): 231-237.

Dittenhofer M 1994. Strategy for the internal audit engagement. Managerial Auditing Journal, 9(8): 1317.

Engle TJ, Joseph GW 2001. Use of control self-assessment in audits. CPA Journal, 71(8): 46-49.

Fernandez-Laviada A 2007. Internal audit function role in operational risk management. Journal of Financial Regulation and Compliance, 15(2): 143-155.

Flesher DL, De Magalhaes R 1995. Electronic workpapers. Internal Auditor, 52(4): 38-43. 
Flowerday S, Blundell AW, Von Solms R 2006. Continuous auditing technologies and models: A discussion. Computer and Security, 25(5): 323-331.

Garrity EJ, O’Donnell JB, Sanders GL 2006. Continuous Auditing and Data Mining. From <http: //www.igiglobal.com/chapter/continuous-auditing-mining/ 10596>. (Retrieved on 2 March 2012).

Glover SM, Romney MB 1998. The next generation software. Internal Auditor, 55(4): 47-53.

Graves S, Marsh TA, Ahmed B 2003. The real story on control self-assessment. Academy of Accounting and Financial Studies Journal, 7(1): 45-53.

Griffiths DM 2006. Risk-based Internal Auditing: Three Views on Implementation. From <www. readbag. com/internalaudit-files-implementation-implementing-rbia-v1-1>. (Retrieved on 2 March 2012).

Hall TW, Hunton JE, Pierce BJ 2002. Sampling practices of auditors in public accounting, industry and government. Accounting Horizons, 16(2): 125-136.

Hubbard LD 2002. CSA by any name. Internal Auditor, 59(6): 22-23.

Hudson ME 1998. CAATs and compliance. Internal Auditor, 55(2): 25-27.

Institute of Directors (IoD) 2009. King Report on Corporate Governance for South Africa. Johannesburg: IoD.

Institute of Internal Auditors (IIA) 2010. The International Professional Practice Framework (IPPF). Altamonte Springs, FL: The IIA.

Institute of Internal Auditors Research Foundation (IIARF) 2010. The Component of the CBOK Study. Altamonte Springs, FL: The IIARF.

Institute of Internal Auditors South Africa (IIA SA) 2012. Draft Report - The IIA South Africa Report on the Global Internal Audit Survey: A Component of the CBOK Study. Bedfordview, Johannesburg.

Jacobus, D 2015. New paradigm of managing risks: Risk and control self-assessment. Agriculture and Agricultural Science Procedia, 3: 32-34.

Joseph GW, Engle TJ 2005. The use of control selfassessment by independent auditors. CPA Journal, 75(12): 38-43.

Kuhn JR, Sutton SG 2010. Continuous auditing in ERM system environments: The current state and future directions. Journal of Information Systems, 24(1): 91-112.

Kutum I, Fraser I, Hussainey K 2015. The application of business risk audit methodology within non-Big-4 firms. Journal of Financial Reporting and Accounting, 13(2): 226-246.

Lamb SW, Svihla WH, Harper JS 2009. The use of statistical sampling and a single point estimator to establish punitive fines in compliance auditing: A cautionary note. Journal of Business and Economics Research, 7(1): 53-62.

Liebowitz J, Rubenstein-Montano B, McCaw D, Buchwalter J, Browning C, Newman B, Rebeck K 2000. The knowledge audit. Knowledge and Process Management, 7(1): 3-10.

Lin S, Pizzini M, Vargus M, Bardhan IR 2011. The role of the internal audit function in the disclosure of material weaknesses. Accounting Review, 86(1): 287323.
Marais M 2004. Quality assurance in internal auditing: An analysis of the standards and guidelines implemented by the IIA. Meditari Accountancy Research, 12(2): 85-107.

Martin JR 2004. Sampling made simple. Internal Auditor, 61(4): 21-24.

McCabe K, Pontillo B, Castillo JA 2007. Continuous improvement. Internal Auditor, 64(1): 83-87.

McCuaig B 1998. Auditing, assurance and CSA. Internal Auditor, 55(3): 43-44.

Melville R 1999. Control self-assessment in the 1990s: The UK perspective. International Journal of Auditing, 3(3): 191-206.

Moeller R 2009. Brink's Modern Internal Auditing: A Common Body of Knowledge. $7^{\text {th }}$ Edition. New Jersey: John Wiley and Sons.

Pathak J, Lind M, Abdolmohammadi M 2010. E-commerce audit judgement expertise: Does expertise in system change management and information technology auditing mediate e-commerce audit judgment expertise? Informatica Economièa, 14(1): 5-20.

Plumly MR, Dudley EM 2002. Building a successful audit organisation. Internal Auditor, 59(4): 54-59.

Pokrovac I, Tušek B, Oluiæ A 2010. The Relation of Risk Management and Internal Audit Function: The Case of Croatia. $5^{\text {th }}$ International Conference, An Enterprise Odysses: From Crisis to Prosperity Challenges for Government and Business, Held in Opatija (Hrvatska) on 26-29 May 2010. From <http: // biblio.irb.hr/prikazi-rad?andlang=EN\%20Croatian\% 20Scientific\%20Biblography\%20CR...andrad=480036>. (Retrieved on 5 March 2012).

Republic of South Africa (RSA) 2009. Internal Audit Framework. $2^{\text {nd }}$ Edition. Pretoria: National Treasury.

Rezaee Z, Reinstein A 1998. The impact of emerging information technology on auditing. Managerial Auditing Journal, 13(8): 465-471.

Sawyer LB, Dittenhofer MA, Scheiner JH 2003. The Practice of Modern Internal Auditing. $5^{\text {th }}$ Edition. Altamonte Springs, FL: The IIA.

Schreiner M 2009. Statistical audit sampling for portfolio at risk in microfinance. Managerial Finance, 35(12): 990-998.

Schroeder D, Singleton T 2010. Implementing the IT related aspects of risk-based auditing standards. CPA Journal, 80(7): 66-71.

Sheffield J, White S 2004. Control self-assessment as a route to organisational excellence: A Scottish Housing Association case study. Managerial Auditing Journal, 19(4): 484-492.

Siers HL, Blyskal JK 1987. Risk management of the internal audit function. Management Accounting, 68(8): 29-35.

Sumners GE, Soileau JS 2008. Addressing internal audit staffing challenges. The EDP Audit Control and Security Newsletter, 37(3): 1-11.

Teeter RA, Alles MG, Vasarhelyi MA 2010. The remote audit. Journal of Emerging Technologies in Accounting, 7(1): 73-88.

Thompson C 2001. CAAT can do. Internal Auditor, 58(3): 73-75

Valls de Almeida N, Pedrosa I 2011. Open Source Data Mining Tools for Audit Purposes. Proceedings of 
the 2011 Workshop on Open Source and Design of Communication. From <http//dl.acm.org/citation. cfm?id=2016724> (Retrieved on 2 March 2012).

Vuchnich A 2008. Using CAATs in preliminary analytical review to enhance the auditor's risk assessment. CPA Journal, 75(5): 38-40.
WebFinance, Inc. 2010. What is Comparability Analysis? Definition and Meaning. From <http: //www. businessdictionary.com/definition/comparabilityanalysis.html> (Retrieved on 22 March 2012).

Zacchea NM 1995. The use of computer modelling and simulation in the audit process. Managerial Auditing Journal, 10(1): 25-30. 